Fetal Diagnosis and Therapy
Fetal Diagn Ther 2011;30:174-179

DOI: $\underline{10.1159 / 000330048}$
Received: April 12, 2011

Accepted after revision: June 7, 2011 Published online: September 8, 2011

\title{
Preschool Neurobehavioral Outcome following Fetal Myelomeningocele Surgery
}

\author{
Enrico Danzer Marsha Gerdes Michael W. Bebbington Jamie Koh \\ N. Scott Adzick Mark P. Johnson \\ The Center for Fetal Diagnosis and Treatment, The Children's Hospital of Philadelphia and The University of \\ Pennsylvania School of Medicine, Philadelphia, Pa., USA
}

\section{Key Words}

Myelomeningocele $\cdot$ Spina bifida $\cdot$ Fetal surgery $\cdot$ Child

Behavior Check List · Premature delivery $\cdot$ Neurobehavioral outcome

\begin{abstract}
Objective: It was the aim of this study to assess the prevalence of preschool neurobehavioral problems in children following fetal myelomeningocele (FMMC) surgery. Methods: Prior to the Management of Myelomeningocele Study, 30 fMMC patients underwent a standardized neurodevelopmental examination at 5 years of age. The prevalence of behavioral problems was assessed by the Child Behavior Check List $(\mathrm{CBCL})$, which includes a total problem score and 2 broad-band indices (internalizing and externalizing problems). $\mathrm{fMMC}$ children were classified as having normal, atrisk or clinically significant scores based on calculated $T$ scores. Results: Twenty-two (73\%) fMMC families completed the evaluation. Mean age at delivery following $\mathrm{AMMC}$ surgery was $35.5 \pm 1.6$ weeks. The prevalence of 'at-risk' or 'clinically significant' scores for internalizing, externalizing and total behavioral problems was similar to general population norms. No difference in overall internalizing $(p=0.19)$, externalizing $(p=0.54)$ and total behavioral $(p=0.18)$ scores was
\end{abstract}

found between non-shunted and shunted FMMC children. However, shunted $\mathrm{FMMC}$ children were more likely to experience anxiety and depressive $(p=0.02)$, pervasive developmental $(p=0.03)$ and withdrawn $(p=0.06)$ behavior. Oppositional defiant, attention deficit and hyperactivity problems were not found. No correlation was found between overall neurodevelopmental outcome and abnormal CBCL scores. Conclusions: $\mathrm{AMMC}$ surgery and subsequent preterm delivery is not associated with increased behavioral problems, impaired social interactions and restricted behavior patterns. Shunted $\mathrm{FMMC}$ children were more likely to have scores in the 'at-risk' or 'clinically significant' range for multiple CBCL subindices. Early detection of behavioral problems following $\mathrm{AMMC}$ surgery provides an opportunity for targeted and timely intervention enabling affected $\mathrm{FMMC}$ children to be socially successful.

Copyright $\odot 2011$ S. Karger AG, Basel

\section{Introduction}

Myelomeningocele (MMC) is a severe and complex congenital defect of the central and peripheral neural system that is associated with significant lifelong morbidity [1]. It is characterized by protrusion of the meninges and

\section{KARGER}

Fax +4161306 1234

E-Mail karger@karger.ch

www.karger.com
(C) 2011 S. Karger AG, Basel

1015-3837/11/0303-0174\$38.00/0

Accessible online at:

www.karger.com/fdt
Mark P. Johnson, MD

The Children's Hospital of Philadelphia

The Center for Fetal Diagnosis and Treatment, 5th Floor Wood Center

34th Street and Civic Center Boulevard, Philadelphia, PA 19104-4399 (USA)

Tel. +1 215590 747, E-Mail johnsonma@email.chop.edu 
neural elements through open vertebral arches leading to variable degrees of paralysis, bladder and bowel incontinence, as well as to skeletal deformities. Nearly all children with MMC develop hindbrain herniation and hydrocephalus as part of the Chiari II malformation. Hydrocephalus adversely affects the intellectual outcome and results in late morbidity and mortality caused by shunt malfunction or infection. Generally, children with MMC are at increased risk of neurocognitive impairments, poor school achievement, language deficits, and visual-motor integration [2]. Moreover, MMC is associated with a wide range of neurobehavioral, social and attention deficit disorders [3-7].

Until a decade ago, treatment of MMC consisted of surgical closure of the spinal canal at birth and lifelong supportive care. However, the severe morbidity and significant mortality associated with MMC combined with compelling experimental evidence in animal models that demonstrated that the neurological deficits in MMC are acquired in fetal life and progress in severity throughout gestation led to consideration of prenatal intervention for MMC $[1,8]$. Retrospective non-randomized and prospective randomized studies demonstrate that the ongoing damage to the spinal cord might be alleviated by fetal MMC (fMMC) surgery before 26 weeks of gestation and that prenatal coverage reverses hindbrain herniation and subsequently favorably impacts on brain stem function, reduces the requirement for ventriculoperitoneal shunt placement and enhances short-term neurofunctional outcome [9-17]. However, these studies also demonstrate that fMMC surgery increases the risks for preterm delivery $[9,10,15,17]$.

Although long-term follow-up is necessary, the implications of these short-term findings are intriguing, if not without controversy. The potential morbidity and mortality resulting from fetal surgery is real, and it is unclear whether the observed benefits will be sustained. For fMMC surgery to be warranted, rigorous follow-up evaluation is necessary to determine whether its potential benefits outweigh its complications and risks. Whether fMMC surgery and subsequent preterm delivery may increase the incidence and severity of neurobehavioral problems in children with MMC is unknown. Therefore, we explored the relationship between neurobehavioral problems in children who underwent fMMC surgery prior to the start of the National Institutes of Health (NIH)sponsored Management of Myelomeningocele Study (MOMS) trial.

\section{Patients and Methods}

This study was approved by the Committee for Protection of Human Subjects Institutional Review Board (IRB No. 2000-112081).

Prior to the beginning of the MOMS trial, 54 MMC fetuses underwent in utero MMC closure at our institution between January 1998 and February 2003. Selection criteria, preoperative evaluation, fetal surgical approach, and short-term outcome have been described elsewhere $[9,15]$. Thirty $(56 \%)$ returned at 5 years of age for comprehensive standardized preschool neurodevelopmental examination as described previously [14]. In addition to the Wechsler Preschool and Primary Scale of Intelligence, third edition (WPPSI-III), fMMC families were asked to complete the Child Behavior Check List for ages 1.5-5 years (CBCL/1.5-5) to assess attention and other behavioral skills.

The WPPSI-III is a widely used, standardized assessment tool shown to be both valid and reliable [18]. The scales are comprised of 10 verbal and performance subtests and yield verbal, performance, full scale and processing speed scores.

The CBCL/1.5-5 is a questionnaire that contains 120 items which are scored on a 3 -point scale $(0=$ not true; $1=$ somewhat or sometimes true; 2 = very or often true) and is used to obtain parental reports of behavior problems and pro-social adaptive skills demonstrated within the previous 6 months $[19,20]$. Results include a total problem score and 2 broad-band groupings that were scored: an internalizing grouping, containing items such as withdrawn behavior, somatic complaints without physical cause and anxious-depressed feelings, and an externalizing grouping, containing items such as aggressive and delinquent behavior. Children were classified as having normal, at-risk or clinically significant scores based on T-score intervals ( $\mathrm{T}$ score $<60$, normal; $\mathrm{T}$ score 61 to $<65$, at risk; $\mathrm{T}$ score $>66$, clinically significant).

The two-sided t test, median test and univariate regression analysis were used as appropriate. $\mathrm{p}<0.05$ was considered statistically significant. All statistical tests were performed using JMP statistical software package (version 7.0, SAS Corporation, Cary, N.C., USA).

\section{Results}

Overall, 22/30 (73\%) fMMC families that returned for the 5-year follow-up evaluation completed the CBCL evaluation. The overall shunt rate was $55 \%(n=12)$, which is lower than the reported $80-90 \%$ ventriculoperitoneal shunt rate in postnatally repaired MMC patients $[21,22]$. That fMMC surgery reduces the need for shunting has also been confirmed by a recently completed randomized trial [17]. The mean age at shunt placement was $4.8 \pm 2.9$ months. Table 1 summarizes the baseline clinical demographics of $\mathrm{AMMC}$ children who completed the CBCL assessment and those that either did not return for the 5 -year follow-up evaluation or did not complete the CBCL assessment. Mean gestational age at delivery and mean birth weight for those fMMC children who did not return 
Table 1. fMMC patient demographics

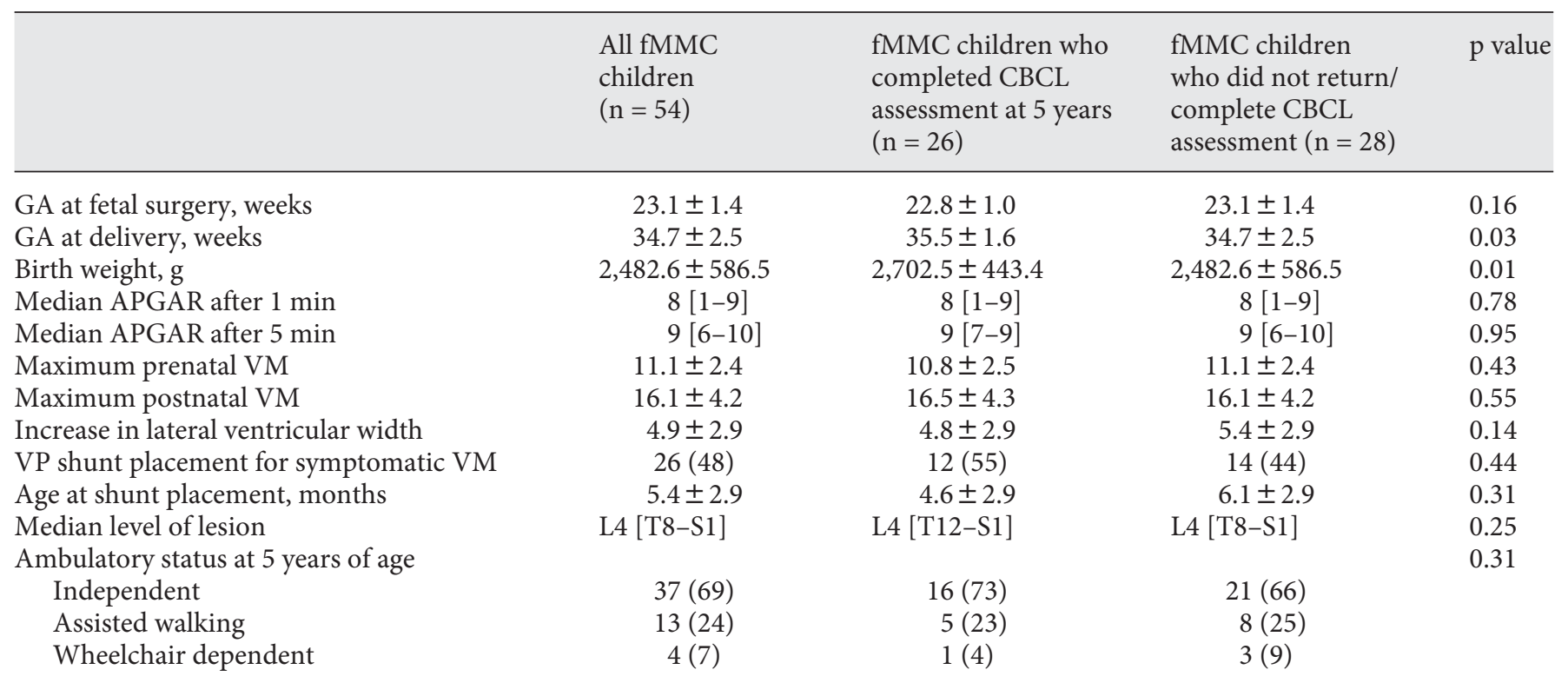

Data are means $\pm \mathrm{SD}$, unless otherwise indicated. Figures in brackets are ranges; figures in parentheses are percentages. GA $=$ Gestational age; $\mathrm{VM}=$ ventriculomegaly; $\mathrm{VP}=$ ventriculoperitoneal; NS = not significant.

Table 2. fMMC CBCL/1.5-5 scores in comparison to normative data

\begin{tabular}{|c|c|c|c|}
\hline & \multicolumn{2}{|c|}{$\begin{array}{l}\text { Prevalence of at-risk or clinically } \\
\text { significant CBCL/1.5-5 }\end{array}$} & \multirow[t]{2}{*}{$\begin{array}{l}\mathrm{p} \\
\text { value }\end{array}$} \\
\hline & $\begin{array}{l}\text { normative } \\
\text { data from } \\
\text { healthy children } \\
\text { born at term } \\
(\mathrm{n}=20)\end{array}$ & $\begin{array}{l}\text { fMMC entire } \\
\text { cohort }(n=22)\end{array}$ & \\
\hline Total problems & 18 & 14 & 0.44 \\
\hline Externalizing problems & 17 & 14 & 0.56 \\
\hline Internalizing problems & 21 & 18 & 0.59 \\
\hline Emotionally reactive & 10 & 14 & 0.38 \\
\hline Anxious/depressed & 8 & 5 & 0.39 \\
\hline Somatic problems & 9 & 14 & 0.27 \\
\hline Withdrawn & 7 & 0 & $<0.01$ \\
\hline Sleep problems & 5 & 5 & 1.0 \\
\hline Attention problems & 7 & 9 & 0.60 \\
\hline Aggressive behavior & 7 & 9 & 0.60 \\
\hline DSM affective & 7 & 9 & 0.60 \\
\hline DSM anxiety & 8 & 9 & 0.80 \\
\hline DSM pervasive & 9 & 9 & 1.0 \\
\hline DSM ADHD & 7 & 0 & $<0.01$ \\
\hline DSM oppositional defiant & 7 & 9 & 0.60 \\
\hline
\end{tabular}

Data are given in percentages. DSM = Diagnostic and Statistical Manual of Mental Disorders; ADHD = attention deficit hyperactivity disorder. was significantly reduced $(\mathrm{p}=0.03$ and 0.01$)$ compared to the study group. The overall ambulatory status and neurodevelopmental outcome of the participating fMMC group and the non-participating fMMC children were similar $(\mathrm{p}=0.31$ and 0.15$)$.

The mean CBCL/1.5-5 T score for total, internalizing and externalizing problems for all $22 \mathrm{fMMC}$ children who participated was $44.1 \pm 12.3$ (median 42, range 28-70), $46.2 \pm 12.0$ (median 43, range 29-70) and 43.4 \pm 11.4 (median 46, range 28-67), respectively. The overall prevalence of at-risk or clinically significant scores for the CBCL/1.5-5 of the fMMC cohort was similar to general population norms (table 2). Of note, none of the $\mathrm{fMMC}$ children were in the 'at-risk' or clinically significant range for withdrawn problems and attention deficit hyperactivity disorder compared with $7 \%$ (p < $0.01)$ and $7 \%(\mathrm{p}<0.01)$ for the normative data, respectively [20].

No difference in overall internalizing $(\mathrm{p}=0.19)$, externalizing $(\mathrm{p}=0.54)$ and total behavioral $(\mathrm{p}=0.18)$ scores was found between non-shunted and shunted fMMC children. However, shunted fMMC children were more likely to experience anxiety and depressive $(\mathrm{p}=0.02)$ as well as pervasive developmental $(\mathrm{p}=0.03)$ problems. Shunted fMMC children also tended to experience withdrawn behavior $(\mathrm{p}=0.06)$ that did not reach statistical 
Table 3. CBCL/1.5-5 scores in fMMC non-shunted and shunted children

\begin{tabular}{|c|c|c|c|}
\hline & $\begin{array}{l}\text { fMMC non-shunted } \\
\text { children }(\mathrm{n}=10)\end{array}$ & $\begin{array}{l}\text { fMMC shunted } \\
\text { children }(n=12)\end{array}$ & $\mathrm{p}$ value \\
\hline Total problems & $47.3 \pm 14.5(48 ; 28-70)$ & $40.4 \pm 8.5(41 ; 28-70)$ & 0.18 \\
\hline Externalizing problems & $43.4 \pm 11.4(46 ; 28-67)$ & $46.6 \pm 13.2(46 ; 28-67)$ & 0.54 \\
\hline Internalizing problems & $42.6 \pm 8.4(42 ; 33-63)$ & $49.2 \pm 14.0(53 ; 29-70)$ & 0.19 \\
\hline Emotionally reactive & $50.1 \pm 0.3(50 ; 50-51)$ & $55.5 \pm 9.8(50-77)$ & 0.11 \\
\hline Anxious/depressed & $50.2 \pm 0.4(50 ; 50-51)$ & $53.4 \pm 6.9(51 ; 50-74)$ & 0.02 \\
\hline Somatic problems & $52.2 \pm 2.6(53 ; 50-58)$ & $56.0 \pm 7.2(53 ; 50-70)$ & 0.36 \\
\hline Withdrawn & $50.9 \pm 1.9(50 ; 50-56)$ & $54.1 \pm 4.4(54 ; 50-63)$ & 0.06 \\
\hline Sleep problems & $52.0 \pm 3.9(50 ; 50-62)$ & $54.3 \pm 9.2(50 ; 50-82)$ & 0.68 \\
\hline Attention problems & $51.3 \pm 2.3(50 ; 50-57)$ & $56.0 \pm 8.9(50-77)$ & 0.41 \\
\hline Aggressive behavior & $50.2 \pm 0.4(50 ; 50-51)$ & $53.6 \pm 6.2(51 ; 50-66)$ & 0.13 \\
\hline DSM affective & $51.0 \pm 1.9(50 ; 50-56)$ & $57.2 \pm 10.2(52 ; 50-79)$ & 0.18 \\
\hline DSM anxiety & $50.6 \pm 1.3(50 ; 50-54)$ & $55.5 \pm 10.4(50 ; 50-81)$ & 0.25 \\
\hline DSM pervasive & $50.2 \pm 0.4(50 ; 50-51)$ & $56.3 \pm 8.0(52 ; 50-72)$ & 0.03 \\
\hline DSM ADHD & $50.8 \pm 1.4(50 ; 50-54)$ & $53.1 \pm 4.8(51 ; 50-64)$ & 0.32 \\
\hline DSM oppositional defiant & $51.0 \pm 1.7(50 ; 50-55)$ & $55.2 \pm 8.6(51 ; 50-73)$ & 0.48 \\
\hline
\end{tabular}

Data are presented as the mean \pm SD (median; range). DSM = Diagnostic and Statistical Manual of Mental Disorders; ADHD = attention deficit hyperactivity disorder.

significance. Overall CBCL/1.5-5 scores for non-shunted and shunted fMMC children are summarized in table 3.

No correlation was found between the WPPSI neurodevelopmental outcome [15] and the prevalence of at-risk or clinically significant CBCL/1.5-5 T scores.

\section{Discussion}

Preterm infants are at increased risk for the subsequent development of neurobehavioral problems in childhood. Particularly, there is a strong association between prematurity and the development of attention deficit/hyperactive disorder, withdrawn and externalizing problems [23-26]. These problems have significant implications for school performance and academic functioning later in life [23].

Despite the promising results of the impact of fMMC surgery on the outcome in affected children, non-randomized and randomized studies show that fetal intervention for MMC is associated with an increased risk of prematurity $[9,10,15,17]$. On average, fMMC children are born at 34 weeks of gestation with $14 \%$ of infants born before 30 weeks of gestation in our initial non-randomized fMMC cohort and with $13 \%$ of infants in the NIHsponsored randomized MOMS trial $[9,17]$. Although the impact of fMMC surgery on neurocognitive and neuro- functional outcome has been examined extensively [10, 12-17], less attention has been paid to the impact of fMMC repair on the overall neurobehavioral outcome. Therefore, we examined the preschool neurobehavioral outcome in children who underwent fMMC prior to the initiation of the NIH-sponsored randomized trial. Our results suggest that the prevalence of neurobehavioral problems following fMMC surgery and subsequent preterm delivery is similar to that reported in population norms (term children without MMC) [20]. Further, while no difference in total, internalizing and externalizing behavioral scores was found between non-shunted fMMC children and those who required shunt placement for progressive ventriculomegaly, shunted infants were more likely to have at-risk or clinically significant scores in several CBCL/1.5-5 internalizing subindices such as anxiety and depressive, pervasive development and withdrawn problems. Whether these neurobehavioral deficits in the internalizing subindices have an impact on school performance, increased strain in interpersonal relationship and inappropriate behavior as these children grow older remains to be determined.

The findings that shunted FMMC children are at increased risk of developing neurobehavioral problems in some internalizing subindices is in agreement with previous reports in postnatally repaired MMC patients who required shunt placement $[3,5,6]$. Although these studies 
also suggest that postnatally repaired MMC patients are at increased risk of developing attention problems, significant attention deficits were not found in our cohort. Of note, our previous follow-up evaluations of children who underwent fMMC surgery at our institution also demonstrated that children who required ventriculoperitoneal shunting following fetal intervention were more likely to continue to present with Chiari II malformationrelated neurological dysfunction, a higher incidence of seizure activity and had lower neurocognitive scores compared to those $\mathrm{AMMC}$ children who did not require a shunt $[12,13,15,16]$. We can only speculate whether children who require shunt placement have more extensive underlying dysgenesis or disorganization of their brain such as increased reduction in cerebral white matter and overall cortical mantle, and/or abnormalities involving the midbrain, cerebellum and corpus callosum that allow a more frequent manifestation of neurocognitive and neurobehavioral problems than their non-shunted fMMC peers.

There are several limitations to our study. First, the sample sizes were small, particularly since not all fMMC families returned for follow-up or completed the CBCL/1.5-5 form, and replication is needed before these results can be confidently generalized to a larger population of children who underwent fMMC surgery. Second, given the retrospective and cross-sectional study design, serial evaluations of neurobehavioral outcomes are warranted to define whether behavioral problems may develop, as these children grow older. These studies are underway. Third, environmental factors, such as parent ed- ucation and socioeconomic status known to be strongly correlated with neurobehavioral outcome may also have impacted on our results. Of note, more than $95 \%$ of our fMMC parents have college degrees and an intact family support system was a requirement before offering fMMC surgery. We appreciate that the higher educational level and socioeconomic status of fMMC families may have been confounding factors in our analysis. Thus, our results may not be generalizable to other MMC populations. Finally, the use of parental information may be a confounding factor. Although substantial agreement has been reported between parent-rated CBCL scores and psychiatrists' clinical severity rating [27], parental report may also be biased by the parents' own psychological or health status. Despite these limitations, the current study provides further insights into the impact of fMMC closure on overall outcomes of children affected by this congenital malformation.

In summary, fMMC surgery and subsequent preterm delivery is not associated with increased behavioral problems, impaired social interactions and restricted behavior patterns. Shunted fMMC children were more likely to have scores in the 'at-risk' or 'clinically significant' range for multiple CBCL subindices. Early detection of behavioral problems following fMMC surgery provides an opportunity for targeted and timely intervention. Since social support of the child and family are an important part of the early follow-up and interventions, these visits may help lessening anxiety and building self-esteems and social skills, enabling affected fMMC children to be socially successful.

\section{References}

1 Danzer E, Flake AW: In utero repair of myelomeningocele: rationale, initial clinical experience and a randomized controlled prospective clinical trial. Neuroembryol Aging 2007;4:165-174.

2 Dennis M, Landry SH, Barnes M, Fletcher JM: A model of neurocognitive function in spina bifida over the life span. J Int Neuropsychol Soc 2006;12:285-296.

3 Loss N, Yeates KO, Enrile BG: Attention in children with myelomeningocele. Child Neuropsychol 1998;4:7-20.

4 Swartwout MD, Cirino PT, Hampson AW, Fletcher JM, Brandt ME, Dennis M: Sustained attention in children with two etiologies of early hydrocephalus. Neuropsychology 2008;22:765-775.
5 Fletcher JM, Ostermaier KK, Cirino PT, Dennis M: Neurobehavioral outcomes in spina bifida: processes versus outcomes. J Pediatr Rehabil Med 2008;1:311-324.

6 Fletcher JM, Brookshire BL, Landry SH, Bohan TP, Davidson KC, Francis DJ, Thompson NM, Miner ME: Behavioral adjustment of children with hydrocephalus: relationships with etiology, neurological, and family status. J Pediatr Psychol 1995;20:109-125.

7 Vinck A, Mullaart R, Rotteveel J, Maasen: Neuropsychological assessment in children with spina bifida. Cerebrospinal Fluid Res 2009;6:6.

8 Adzick NS: Fetal myelomeningocele: natural history, pathophysiology, and in-utero intervention. Semin Fetal Neonatal Med 2010;15: 9-14.
9 Johnson MP, Sutton LN, Rintoul N, et al: Fetal myelomeningocele repair: short-term clinical outcomes. Am J Obstet Gynecol 2003; 189:482-487.

10 Johnson MP, Gerdes M, Rintoul N, Pasquariello P, Melchionni J, Sutton LN, Adzick NS: Maternal-fetal surgery for myelomeningocele: neurodevelopmental outcomes at 2 years of age. Am J Obstet Gynecol 2006;194: 1145-1150.

11 Danzer E, Johnson MP, Bebbington M, et al: Fetal head biometry assessed by fetal magnetic resonance imaging following in utero myelomeningocele repair. Fetal Diagn Ther 2007;22:1-6. 
12 Danzer E, Finkel RS, Rintoul NE, et al: Reversal of hindbrain herniation after maternal-fetal surgery for myelomeningocele subsequently impacts on brain stem function. Neuropediatrics 2008;39:359-362.

13 Danzer E, Finkel R, Gerdes M, et al: The relationship of seizure activity and chronic epilepsy in early infancy and short-term neurodevelopmental outcome following fetal myelomeningocele closure. Neuropediatrics 2010;41:140-143.

14 Danzer E, Gerdes M, Bebbington MW, et al: Lower extremity neuromotor function and short-term ambulatory potential following in utero myelomeningocele surgery. Fetal Diagn Ther 2009;25:47-53.

15 Danzer E, Gerdes M, Bebbington MW, Zarnow DM, Adzick NS, Johnson MP: Preschool neurodevelopmental outcome of children following fetal myelomeningocele closure. Am J Obstet Gynecol 2010;202:450.e1-e9.

16 Danzer E, Gerdes M, Bebbington MW, Koh J, Adzick SN, Johnson MP: Fetal myelomeningocele surgery: preschool functional status using the Functional Independence Measure for children (WeeFIM). Childs Nerv Syst 2011;27:1083-1088.
17 Adzick NS, Thom EA, Spong CY, Brock JW 3rd, Burrows PK, Johnson MP, Howell LJ, Farrell JA, Dabrowiak ME, Sutton LN, Gupta N, Tulipan NB, D'Alton ME, Farmer DL, MOMS Investigators: A randomized trial of prenatal versus postnatal repair of myelomeningocele. N Engl J Med 2011;364:993-1004.

18 Wechsler D: Wechsler Intelligence Scale for Children, ed 3. San Antonio, The Psychological Corporation, Harcourt Brace and Company, 1991.

19 Achenbach TM, Ruffle TM: The Child Behavior Checklist and related forms for assessing behavioral/emotional problems and competencies. Pediatr Rev 2000;21:265-271.

20 Achenbach TM, Rescorla LA: Child Behavior Checklist for Ages 1.5-5. Burlington, University of Vermont, 2000.

21 Dias MS, McLone DG: Hydrocephalus in the child with dysraphism. Neurosurg Clin N Am 1993;4:715-726.
22 Rintoul NE, Sutton LN, Hubbard AM, et al: A new look at myelomeningoceles: functional level, vertebral level, shunting, and the implication for fetal intervention. Pediatrics 2002;109:409-413.

23 Bhutta AT, Cleves MA, Casey PH, Cradock MM, Anand KJ: Cognitive and behavioral outcomes of school-aged children who were born preterm: a metaanalysis. JAMA 2002; 288:728-737.

24 Gray RF, Indurkhya A, McCormick MC: Prevalence, stability, and predictors of clinically significant behavior problems in low birth weight children at 3,5 , and 8 years of age. Pediatrics 2004;114:736-743.

25 Hack M, Flannery DJ, Schluchter M, Cartar L, Borawski E, Klein N: Outcomes in young adulthood for very-low-birth-weight infants. N Engl J Med 2002;346:149-157.

26 van Baar AL, Vermaas J, Knots E, de Kleine MJ, Soons P: Functioning at school age of moderately preterm children born at 32 to 36 weeks' gestational age. Pediatrics 2009;124: 251-257.

27 Verhulst FC, van der Ende J: Assessment of child psychopathology: relationships between different methods, different informants and clinical judgment of severity. Acta Psychiatr Scand 1991;84:155-159. 